\title{
Research on the national standard of the minimum allowable values of energy efficiency and energy efficiency grades for key sewage treatment equipment
}

\author{
Huang Jin ${ }^{1,}$, Wang Yueping ${ }^{2}$, Zhang Xinheng ${ }^{2}$, Chen Bin $^{3}$, Shi Ming ${ }^{4}$, Ling Jianjun ${ }^{5}$, Wang Wensheng ${ }^{6}$, Wang Qijun ${ }^{7}$, \\ Zhang Xiaoxin ${ }^{1}$, Lin Ling ${ }^{1}$ \\ ${ }^{1}$ China National Institute of Standardization, 100191 Beijing, China \\ ${ }^{2}$ MCC HUATIAN Engineering \& Technology Corporation, 243011 Ma'anshan, China \\ ${ }^{3}$ Nanjing Lanshen Pump Corp.LTD., 211500 Nan Jing, China \\ ${ }^{4}$ Brooklyn Nanjing environmental protection equipment co., LTD, 211500 Nan Jing, China \\ ${ }^{5}$ Lingzhi Environmental Protection Group, 214215 Yi Xing, China \\ ${ }^{6}$ Nanjing beit environmental protection general equipment manufacturing co., LTD, 211500 Nan Jing, China \\ ${ }^{7}$ Jiangsu Tianyu Environmental Protection Group CO.LTD, 225268 Yang Zhou, China
}

\begin{abstract}
This paper expounds the background and significance of the national standard of the development on the minimum allowable values of energy efficiency and energy efficiency grades for submersible pushing-flow agitator and rotary aerator in wastewater treatment, and introduces the general principle of the standard, the determination of the minimum allowable values of energy efficiency, the division of the energy efficiency grades for them, as well as the testing and calculation methods. It hopes to eliminate the production of the high energy consumption sewage treatment equipment, and enhance their level of the energy efficiency effectively through development and implementation of the national standard.
\end{abstract}

\section{Background and significance of the national standard of the minimum allowable values of energy efficiency and energy efficiency grades for key sewage treatment equipment}

\subsection{Research advance in China and abroad}

\subsubsection{Submersible Pushing-flow agitator}

The submersible pushing-flow agitator is the comprehensive and multi-disciplinary sewage treatment equipment that features broad technological coverage and high technological contents. The submersible pushing-flow agitator mainly includes electric motor, electrical control equipment, gear reducer, hydraulic components and hoisting mechanism. It's the integration of general machinery, fluid machinery, hoisting machinery and electromechanical equipment. There're three types of submersible pushing-flow agitators in terms of rotational speed and main functions, low-speed, mid-speed and high-speed submersible pushing-flow agitators. The submersible pushing-flow agitators run in the underwater working environment, and in the sewage treatment or river regulation projects with extremely adverse working conditions, therefore, there's a high requirement for all their functions and especially sealing performance and hydraulic components. In addition to professional technological research, development and design, their manufacturing technique proves very strict so that a high standard for safety, energy conservation, reduction of energy consumption and increase in energy efficiency can be satisfied.

In the late 1970's, Germany's ITT introduced the world's first submersible agitator. Later on, many foreign companies, including Denmark's Grundfos, Switzerland's Sulzer and Germany's ITT started the research and development of submersible pushing-flow agitators. Those foreign submersible pushing-flow agitators enjoyed some advantages in term of materials, heat treatment and manufacturing technique, but they had expensive components, high maintenance costs and high energy consumption. Users have to make much investments in the early stage and high operation costs later.

China's earliest submersible pushing-flow agitators were all imported from abroad. In the mid- 1990's, China started its independent research and development work after the early imitation gradually gave away to the absorption of foreign technologies. However, since China had lagged far behind the foreign countries in the light of the selection of component materials, production, manufacturing and heat treatment, the home-made submersible pushing-flow agitators shared the problems like high failure rate, short service life and high energy consumption. In recent years, some environmental

\footnotetext{
* Corresponding author: huangjin@cnis.gov.cn
} 
protection equipment manufacturers in China have paid much attention to innovation research and development of usher submersible agitators. After some repeated verification procedure that involves research, development, simulation test, pilot-scale test, operation verification, and improvement, China has developed the cost-efficient submersible pushing-flow agitators. Some of them have enjoyed a noticeable increase in reliability of operation, service life, performance and energy efficiency, and attained and even surpassed the world's advanced level.

\subsubsection{Rotary aerator}

The aerator involved in sewage treatment is critical to pre-treatment of aquatic organisms and treatment of organisms in waste water whose function is to transfer oxygen in the air to the liquid of aeration pool to achieve the purpose of biological treatment. In most cases, the aerator is divided into four types:, blower aerator (smallhole bottom aeration), surface aerator (surface aerator with vertical shaft and surface aerator with horizontal shaft), underwater aerator (self-absorbed and air-supply fluid injecting aerator) and oxygen aerator. The rotary aerator as mentioned in this paper can be divided into surface aerator with vertical shaft (mainly inverted umbrella type, rotary aerator with vertical shaft (mainly rotary disc and brush) and self-absorbed impeller aerator when it comes to the installation methods.

The use of rotary aerator for sewage treatment abroad started in the 1960's. The first generation of inverted umbrella-type surface aerators with vertical shaft, in which Holland's DHV-type aerator and America's Hubert-type aerator developed by EIMCO were the typical examples. The theoretical dynamic efficiency was no more than $1.8 \sim 2.1 \mathrm{kgO} 2 / \mathrm{kW} \cdot \mathrm{h}$. In the 1970 's, the rotary aerators with horizontal shaft were promoted by Envirex, a U.S.-based company when Orbal Oxidation Ditch started to be used in South Africa. Their performance of fluid propelling was slightly better and enjoyed broad use within a given period. When the same amount of energy was consumed, their performance was far lower than rotary aerators with vertical shaft. In 2001, America's Westech developed ALNDY-7 type rotary aerators with vertical shaft. Their aeration performance was raised and the theoretical dynamic efficiency was as high as $2.5 \sim 2.7 \mathrm{kgO} 2 / \mathrm{kW} \cdot \mathrm{h}$.

China's aerators didn't appear until the 1980's. At the outset, China mainly introduced Holland's DHVtype aerator and America's Hubert-type aerator with vertical shaft as developed by EIMCO. Because of the limited knowledge about aerators and the failure to understand the essence of aeration technology, the oxygenation capacity can't satisfy the design demand in the on-site use and the energy consumption remains at a high level. As the technique of Orbal Oxidation Ditch from abroad was promoted in the market, the domestic sewage treatment plants gradually used the rotary aerators with vertical shaft. Yet because the aeration law of aerators wasn't understood, no breakthroughs were made in the key aeration technology. In recent years,
China's aerator manufacturers have made more efforts in innovative designs, production, research and development in the light of oxygenation performance and transmission stability. Through introduction, digestion and absorption to improvement and proprietary research and development, China's aerators have seen a major enhance in theoretical dynamic efficiency and energy efficiency ratio when compared to the early development period, and have reached the world's leading standard by performing far better than foreign aerators of same type.

\subsection{Voluntary product standards}

The national standard for submersible pushing-flow agitators was unavailable in China before 2017. Only two existing industry standards, including the Specifications for Environmental Protection Product: Submersible pushing-flow Agitators (the environmental protection industry standard HJ/T279-2006), and Submersible Agitator (the urban construction industry standard CJ/T109-2007). Due to the historical defects for the development of industry standards, less sufficient knowledge and research of submersible pushing-flow agitators, as well as limited design capacity and manufacturing technique, the industry standards weren't comprehensively expressed. In particular, these standards failed to cover safety, energy conservation, reduction of energy consumption and increase in energy efficiency in an intensive sense and the technical specifications and regulations couldn't meet the users' demands for the technical performance of products. As the current requirements for product optimization, technical improvement, and energy conservation and emission abatement prove increasingly rigorous, it's imperative to design the effective national standard to regulate the production and manufacturing activities and guide the positive competition and development in the industry.

The national standard for Pusher Submersible Agitators (GB/T33566-2017) was officially published on May 12, 2017, and came into effect on December 1, 2017. This marks that China's production, manufacturing, model selection and application of homemade submersible pushing-flow agitators will have the specific rules to follow and have their quality traceable. This national standard specifies the classification and naming of submersible pushing-flow agitators, technical specifications for key parts (including electric motor, electrical control equipment, gear reducer, impeller, dynamic and static sealing equipment, case, bearing, fastener and hoisting mechanism), testing methods, testing rules, label, packaging, transportation and storage. In particular, there're some detailed and strict rules for safety, reliability, specific power, work performance and service life of submersible pushing-flow agitator. This national standard is highly operable, farsighted, and definitely instructive. This standard examines the high reliability and energy efficiency of submersible pushingflow agitators, which represent the design level and manufacturing strength in most manufacturers of 
submersible pushing-flow agitators and can meet the users' demands to the utmost degree.

The existing industry standards for aerators mainly include Specifications for Environmental Protection Product -- Vertical Shaft Mechanical Surface Aerator (HJ/T247-2006), and Submersible Agitator (the urban construction industry standard CJ/T109-2007), Inverted Umbrella Type Surface Aerators (JB/T 10670-2014), Oxygen Transfer Measurement of Aerators in Clean Water (CJ/T 3015.2-1993), and Specifications for Environmental Protection Product: Rotary Disc Aerator (HJ/T280). Most of these standards have existed for years. The national standard for Submersible Aerator (GB/T27872-2011) was officially published in December 2011, and came into force on September 1, 2012. This standard details the classification, structural composition, basic specifications (including working environment and condition, appearance, material, impeller, sealing parts, submersible electric motor, and deceleration mechanism), specification for assembly and performance of submersible self-absorbed aerators and submersible air-supply aerators, as well as the testing methods and rules, labels, packaging, transportation and storage. The specification for the performance of submersible aerator mainly involves oxygenation performance, agitation performance, fault-free working hours, designed life, protection unit, noise and electrical control equipment. The latest standards concerned is Surface Aerator with Vertical Shaft (GB/T 35183-2017) in 2017. This national standard provides the terms, definitions, classification models, basic parameters, requirements, testing methods and rules, bales, packaging, transportation and storage of surface aerators with vertical shaft. The standards offers the technical support for regulating and guiding the design, manufacturing and performance testing of this type of equipment. When compared to the previous industry standards, this standard has a broader scope, more product types and models, more contents in the context of technical advancement, and finds an effective solution to the repeated use of terms in all the existing standards. In this sense, this standard is well suitable and operable.

\subsection{Necessity for the compulsory standard on energy efficiency}

Both submersible pushing-flow agitators and rotary aerators are widely used in the sewage treatment plants, so their energy efficiency can have a direct effect on the sewage treatment costs. The energy consumption of aerators usually account for over $65 \%$ of total energy consumption in sewage treatment plants. As far as energy consumption is concerned, agitators was ranked the third place, only next to aerators and pumps. Now China mainly uses submersible pushing-flow agitators and rotary aerators in use of quite a few sewage treatment plan. The domestic companies only consider such factors as service life, reliability and durability, but fail to make selections for the purpose of energy conservation and consumption reduction. As a result, the producers and designers rarely pay attentions to the energy efficiency of products, and those products with high energy consumption and low energy efficiency still have a giant market. The malignant market competition is really a problem of much concern, but the products with high energy efficiency and low energy consumption can't be promoted and used. In this case, after the voluntary product standards like Submersible pushingflow Agitators (GB/T33566-2017) and Surface Aerators with Vertical Shaft (GB/T 35183-2017) are implemented, it's imperative to develop some compulsory standards for energy efficiency in order to further boost the progress in the enterprises' energy-saving technologies, enhance energy efficiency level, encourage advanced technologies, eliminate backward technologies, and regulate the industry development.

Since China has a increasingly higher requirement for output water quality index, there's also an increase in the requirement for the quality of submersible pushingflow agitators and rotary aerators used in the process of sewage treatment and for the energy efficiency. The development of compulsory standards for energy efficiency will also provide the technical basis for implementing the energy conservation and environmental protection policies and systems including energy conservation law, certification of energy-saving products, energy-efficiency labels, energy-efficiency "pacesetter", environmental protection equipment, and product evaluation in the form of standards.

In July 2014, the development plans for two international standards were put on agenda. National Standardization Technical Committee of Environmental Protection Industry (SAC/TC275) and National Standardization Technical Committee on Energy Fundamentals and Management (SAC/TC20) co-organized the development of these standards. They mainly study energy efficiency grade, technical specification and testing method of submersible pushingflow agitators and rotary aerators used in sewage treatment equipment.

\section{Development of the national standard of the minimum allowable values of energy efficiency and energy efficiency grades for key sewage treatment equipment}

\subsection{Principles for development of standard}

The development of the national standard of the minimum allowable values of energy efficiency and energy efficiency grades for sewage treatment equipment should follow the following principles:

- The national policies on energy conversation and environmental protection should be matched, and the national industry policies should be closely connected;

- The requirements of technical progress, proprietary innovation, energy conservation and industry development for the energy-efficiency standard should be highlighted so that the standard can guide innovative design and structure improvement producers and 
manufacturers and the environment-friendly products are really energy efficient.

- Users need to be given guidance of their efforts to reduce sewage treatment costs and reduce energy consumption with the model selection of key sewage treatment equipment, according to the principle of regulating market order, satisfying market demands and protecting consumers' interests.

- Technical breakthrough in China's submersible pushing-flow agitators could be achieved, raising the products' energy efficiency and break the monopoly of foreign brands through the development and implementation of energy-efficiency standards according to the international integration principle.

\subsection{Key terms and definitions}

- The national standard of Submersible pushing-flow Agitators (GB/T33566-2017) is the first standard to propose the concept of "specific power", which is an indicator used to appraise the work performance of submersible pushing-flow agitators. In the stipulated test conditions, when the sedimentation of water body is prevented, specific power refers to the ratio of electric consumption to size of water body. The national standard of the Minimum Allowable Values of Energy Efficiency and Energy Efficiency Grades for Sewage Treatment Equipment of Submersible pushing-flow Agitators for Sewage Treatment should be consistent with the national standard of Submersible pushing-flow Agitators (GB/T33566). The indicator "specific power" is still used as the evaluation basis of energy efficiency. It's defined as "the input power affecting the water body each cubic meter when flow rate of water body is less than $0.3 \mathrm{~m} / \mathrm{s}$ in the specified test condition". The lower specific power is, the lower the general power consumed by wave-making of water body each cubic meter is. This proves that the energy consumption for useful power (that ensures movement of sludge instead of sedimentation) has a high proportion, but the energy consumption for useless power has a low proportion. As the ideal equipment with high energy efficiency, it can be widely promoted and used. In contrast, higher specific power means that the energy consumption for useless power has a high proportion, and the equipment has a low energy efficiency. So the equipment can be categorized as the products with low or backward production capacity. Based on the concept of specific power, the standard defines the term of "minimum allowable values of energy efficiency of submersible pushing-flow agitators" as "the maximum specific power allowable for submersible pushing-flow agitators under the specified test conditions".

- The energy consumption indicator of rotary aerators for sewage treatment is directly related to the users' costs in the use of sewage treatment equipment. So it's what users are concerned about and a key index for manufacturers to display their technical level. Therefore, the national standard of Minimum Allowable Values of Energy Efficiency and Energy Efficiency Grades of Rotary Aerators for Sewage Treatment introduces the term of "energy efficiency ratio" as the evaluation basis of energy efficiency to perform the comprehensive assessment of aerators' overall efficiency, performance and energy consumption. This term is defined as "the ratio of oxygen amount transferred to clean water with no soluble oxygen to total electrical consumption by rotary aerators within the unit time in the specified test condition". The higher energy efficiency ratio, the higher ratio of energy consumption for useful power in aerators, and the lower ratio of energy consumption for useless power. As the ideal equipment with high energy efficiency, it can be widely promoted and used. In contrast, lower energy efficiency ratio means that ratio of energy consumption for useful power in aerators is lower and the equipment's energy efficiency is lower. So the equipment can be categorized as the products with low or backward production capacity. Based on the concept of energy efficiency ratio, the standard defines the term of "minimum allowable values of energy efficiency of rotary aerators" as "the maximum specific power allowable for rotary aerators under the specified test conditions".

\subsection{Technical specifications for minimum allowable values of energy efficiency and energy efficiency grades}

- Minimum allowable values of energy efficiency and energy efficiency grades of submersible pushing-flow agitators

When the standard is developed, the task force set the statistical form of energy efficiency parameters and adopts the method of incomplete statistics. For those domestic manufacturers with considerable production and sales of submersible pushing-flow agitators, the actual testing, data collection, and survey, statistics and analysis of energy efficiency parameters are conducted according to three product models including low-speed, mid-speed and high-speed submersible pushing-flow agitators. The energy efficiency parameters cover product specification, flow rate, effective plug flow distance along the direction of shaft, effective agitation radius and specific power. The statistics and analysis of specific power can refer to Table 1.

Table 1. Statistics of market share of specific power value of submersible pushing-flow agitators

\begin{tabular}{|c|c|c|}
\hline $\begin{array}{c}\text { Specific } \\
\text { power } \\
\text { value } \\
\mathrm{E}\left(\mathrm{W} / \mathrm{m}^{3}\right)\end{array}$ & Market share & Total ratio \\
\hline \multicolumn{3}{|c|}{ Low speed } \\
\hline $\mathrm{E} \leq 1.5$ & $8 \%$ & $8 \%$ \\
\hline $\begin{array}{c}1.5< \\
\mathrm{E} \leq 2.0\end{array}$ & $20 \%$ & $28 \%$ \\
\hline $\begin{array}{c}2.0< \\
\mathrm{E} \leq 3.0\end{array}$ & $52 \%$ & $80 \%$ \\
\hline $3.00<\mathrm{E}$ & $20 \%$ & $100 \%$ \\
\hline \multicolumn{3}{|c|}{ Mid-speed } \\
\hline
\end{tabular}




\begin{tabular}{|c|c|c|}
$\mathrm{E} \leq 2.0$ & $6 \%$ & $6 \%$ \\
\hline $\begin{array}{l}2.0< \\
\mathrm{E} \leq 4.0\end{array}$ & $18 \%$ & $24 \%$ \\
\hline $\begin{array}{l}4.0< \\
\mathrm{E} \leq 6.0\end{array}$ & $58 \%$ & $82 \%$ \\
\hline $6.0<\mathrm{E}$ & $18 \%$ & $100 \%$ \\
\hline \multicolumn{3}{|c|}{ High speed } \\
\hline $\mathrm{E} \leq 2.0$ & $6 \%$ & $6 \%$ \\
\hline $2.0<$ \\
$\mathrm{E} \leq 4.0$
\end{tabular}

The classification of energy efficiency grades is conducted according to the existing national standards, survey statistical form and current technology and performance in the market. Based on the survey, statistics and analysis of specific power value as stated above, the energy efficiency grades of low-speed, midspeed and high-speed submersible pushing-flow agitators fall into three grades(as indicated in Table 2). Specifically, Grade 1 represents the highest energy efficiency. The minimum allowable values of energy efficiency for submersible pushing-flow agitators of all the grades shall not be higher than specific power of Grade 3 in Table 2. The market share of the low-speed, mid-speed and high-speed submersible pushing-flow agitators of all energy efficiency grades please refer to Table 2.

Table 2. Energy efficiency grades of submersible pushingflow agitators

\begin{tabular}{|c|c|c|c|}
\hline \multirow{2}{*}{$\begin{array}{c}\text { Energy } \\
\text { efficienc } \\
\text { y grades }\end{array}$} & $\begin{array}{c}\text { Low-speed } \\
\text { submersible } \\
\text { pushing-flow } \\
\text { agitator }\end{array}$ & $\begin{array}{c}\text { Mid-speed } \\
\text { submersible } \\
\text { pushing-flow } \\
\text { agitator }\end{array}$ & $\begin{array}{c}\text { High-speed } \\
\text { submersible } \\
\text { pushing-flow } \\
\text { agitator }\end{array}$ \\
\hline Grade 1 & 1.50 & 2.00 & 2.50 \\
\hline Grade 2 & 2.00 & 4.00 & 4.50 \\
\hline Grade 3 & 3.00 & 6.00 & 6.00 \\
\hline
\end{tabular}

Note 1:Low-speed submersible pushing-flow agitators refer to the equipment whose propeller runs at a rate of less than $120 \mathrm{r} / \mathrm{min}$, and which is mainly used for agitation, mixing and long-distance plug flow to raise the fluid rate and prevent sedimentation.

Note 2 Mid-speed submersible pushing-flow agitators refer to the equipment whose propeller runs at a rate of less than $120 \mathrm{r} / \mathrm{min} \sim 350 \mathrm{r} / \mathrm{min}$, and which is mainly used for agitation, mixing and long and short-distance plug flow to raise the fluid rate and prevent sedimentation.

Note 2 Mid-speed submersible pushing-flow agitators refer to the equipment whose propeller runs at a rate of higher than $350 \mathrm{r} / \mathrm{min} \sim 350 \mathrm{r} / \mathrm{min}$, and which is mainly used for agitation, mixing and shortdistance plug flow to raise the fluid mixing results and prevent sedimentation.

- Minimum allowable values of energy efficiency and energy efficiency grades of rotary aerators

Different types of rotary aerators differ in minimum allowable values of energy efficiency, and the minimum allowable values of the lowest energy efficiency should be determined according to the survey statistics. The task force set the statistical form of energy efficiency parameters. The actual testing and data collection of energy efficiency parameters are conducted. The energy efficiency parameters cover product specification, oxygenation capacity, shaft power, power of electric motor, theoretical power efficiency and energy efficiency ratio.

There're only several manufactures of rotary aerators with vertical shafts, and their products have a market share of about $20 \% \sim 25 \%$. The task force's surveys cover more than $75 \%$. There're about 50 manufacturers of rotary aerators with horizontal shafts, and their products have a market share of about $25 \%$. The selfabsorbed propeller aerators are usually used for industrial waste water with considerable water depth. There're about 20 manufacturers. Referring to the existing national standard Submersible Aerators (GB/T27872-2011), the minimum allowable values of energy efficiency are to be determined. Table 3 shows the survey statistics of energy efficiency ratio of rotary aerators.

Table 3. Statistics of market share of energy efficiency ratio of rotary aerators

\begin{tabular}{|c|l|c|}
\hline $\begin{array}{c}\text { Energy efficiency } \\
\text { ratio } \mathrm{kgO}_{2} / \mathrm{kWh}\end{array}$ & $\begin{array}{c}\text { Market } \\
\text { share }\end{array}$ & Total ratio \\
\hline \multicolumn{3}{|c|}{ Vertical } \\
\hline $\mathrm{E} \geq 3.30$ & $14.3 \%$ & $14.3 \%$ \\
\hline $3.20 \leq \mathrm{E}<3.30$ & $14.3 \%$ & $28.6 \%$ \\
\hline $2.50 \leq \mathrm{E}<3.20$ & $57.1 \%$ & $85.7 \%$ \\
\hline $\mathrm{E}<2.5$ & $14.3 \%$ & $100 \%$ \\
\hline \multicolumn{3}{|c|}{ Horizontal } \\
\hline $\mathrm{E} \geq 3.00$ & $6 \%$ & $6 \%$ \\
\hline
\end{tabular}


energy efficiency and energy efficiency grades responds to the development progress of this era and to the requirements from a series of planning policies for energy conservation and emission reduction and standardized development, including "Made in China 2025", "Energy Efficiency 'Pacesetter", "Plan for Standardization and Quality Increase of Equipment Manufacturing Industry and "Guiding Opinions for Taking Quality Increase Actions. In the standard, the minimum allowable values of energy efficiency and the highest energy efficiency grade that are determined according to the survey statistical form and the actual level. The standard represents the technical progress and development of submersible pushing-flow agitators and rotary aerators in the sewage treatment industry. And the standard represents China's most advanced level and attains the world's leading position, and can more effectively help manufacturers and users gain the technical capacity of delicacy energy-saving operation.

- The national standard of the minimum allowable values of energy efficiency and energy efficiency grades of submersible pushing-flow agitators is China's first standard of energy efficiency of key environmental protection equipment in sewage treatment industry. The development and implementation of this compulsory standard will earnestly enhance the market access threshold of key environmental protection equipment in sewage treatment industry, enhance the technical level of similar products throughout China, eliminate those quality with poor quality and high energy consumption and promote the innovation and progress of energy conservation technology. What's more, they can also promote the construction of testing capacity and raise the testing level of the national third-party testing authorities, effectively remove the manufacturing defects and the supervisory problems, and regulate market competition order to optimize industrial structure, sharpen market competitiveness and create industry pattern with coordinated development.

\section{Acknowledgment}

This work was supported by the National Key R\& D Program of China (2018YFF0213201).

\section{References}

1. GB/T 33566 Pusher Submersible agitator. (2017).

2. GB 18613 Minimum allowable values of energy efficiency and energy efficiency grades of small and medium three-phase asynchronous motors.(2012).

3. JB/T 12579 Multi-function high-efficient aerator. (2015).

4. Huang Jin, Lin Ling, Guo Jun, Li Jianguo, Wang Yongzhong. IOP Conf.Series: Earth and Environmental Science 94(2017).

5. GB/T 35183 Vertical shaft surface aerator. (2017).

6. HJ/T279 Specifications for environmental protection product Pusher submersible agitator. (2006).
7. GB/T27872 Submersible aerator.(2011). 